\title{
EFFECT OF EARTHQUAKE ON DRIVING OF VEHICLE BASED ON QUESTIONNAIRE SURVEY
}

\author{
By Kazuhiko KAWASHIMA*, Hideki SUGITA** and Takashi KANOH***
}

\begin{abstract}
Vibration characteristics of motor vehicles and driver's reaction during an earthquake are studied through questionnaire to the drivers who were in driving in a region with the JMA seismic intensity of $\mathrm{V}$ during the Nihon-kai-chubu Earthquake of 1983 and the Chiba-ken-oki Earthquake of 1987. Emphasis is placed on driver's recognition of earthquake, the reason why drivers recognized the earthquake and driving situation during the earthquake.

It is concluded from the study that degree of driver's recognition of an earthquake highly depends on driving situation. Approximately fifty percent of the total drivers immediately recognized the outbreak of the earthquake from the abnormal vibration of vehicles, followed by swinging of electric poles and street signs, and vibration of houses.

Keywords : earthquake, driving, vibration of motor vehicle, Nihon-kai-chubu earthquake, Chiba-ken-oki earthquake
\end{abstract}

\section{INTRODUCTION}

Although no accurate data are available, the number of motor vehicles owned in 1923 was only 4500 in Tokyo city and only 13000 for the nation. In fact, from the photographs showing resident's evacuation in Tokyo city immediately after the 1923 Kanto Earthquake, walking, bicycle and large carts are the principal means of evacuation. On the contrary, as a direct result of today's progress of automobile society, the number of motor vehicles owned greatly increased and is estimated as 43 million. The number of registered drivers has reached to 55 million which corresponds to $50 \%$ of the total population.

As demand for highway traffic increases, safety required for roads significantly increases even during an earthquake. Serious retardation of vehicles during evacuation and block of transportation due to vehicles left on road are the serious concerns in earthquake hazard mitigation in urban area. It is therefore strongly required to reveal how the vehicles vibrate and how the drivers react in the event of occurrence of earthquake. However, only few studies have so far been made and reported from this point of view.

The present paper presents a result on the vibration characteristics of motor vehicles and driver's reaction during an earthquake based on the results of the answers to questionnaire obtained from vehicle drivers who were in driving through a region with the Japan Meteorological Agency's (JMA) seismic intensity of V during the Nihon-kai-chubu Earthquake of 1983 and the Chiba-ken-oki Earthquake of 1987.

\footnotetext{
* Member of JSCE, Dr. Engr., Head of Earthquake Engineering Division, Earthquake Disaster Prevention Department, Public Works Research Institute, Ministry of Construction (Tsukuba Science City, Ibaraki-ken, Japan)

** Member of JSCE, Research Engineer, ditto.

*** Member of JSCE, Assistant Research Engineer, ditto.
} 


\section{OUTLINE OF EARTHQUAKE}

The Nihon-kai-chubu Earthquake occurred at 12:00 on May 26, 1983 at $90 \mathrm{~km}$ offshore of Akita-ken. Earthquake magnitude was registered as 7.7. Fig. 1 shows a distribution of seismic intensity as well as the aftershock area designated by JMA. The distribution of seismic intensity during the Chiba-ken-oki Earthquake which will be described later is also presented in this figure. The seismic intensity at west half of Akita-ken where motor vehicles in study were located was $\mathrm{V}$. The aftershock area extends in $120 \mathrm{~km}$ and $60 \mathrm{~km}$ in NS and EW directions, respectively. Fig. 2 (a) represents attenuation of peak ground accelerations observed with the strong motion network of the Public Works Research Institute and the Port and Harbor Research Institute ${ }^{1)}$. It should be noted that instrument correction was made for the records. Because the epicentral distance at west half of Akita-ken is between $100 \mathrm{~km}$ and $170 \mathrm{~km}$, the peak ground acceleration in horizontal direction was ranging from $0.4 \mathrm{G}$ to $0.03 \mathrm{G}$ at the area.

The Chiba-ken-oki Earthquake occurred $10 \mathrm{~km}$ from coast of Chiba-ken at 11:08 on December 17, 1987. Although earthquake magnitude was 6.7 , the Tokyo Metropolitan area was widely shaken extensively. The distribution of seismic intensity is shown in Fig. 1. The seismic intensity at Chiba-ken where motor vehicles in study were located was V. Fig. 2 (b) represents an attenuation of peak ground accelerations observed with the strong motion network of PWRI and PHRI. Peak ground acceleration in horizontal direction was in a range from $0.3 \mathrm{G}$ to $0.03 \mathrm{G}$ in Chiba-ken.

The Nihon-kai-chubu Earthquake of 1983 and the Chiba-ken-oki Earthquake of 1987 will be designated hereinafter as the $\mathrm{N}$-Earthquake and the $\mathrm{C}$-Earthquake, respectively.

\section{QUESTIONNAIRES ON DRIVING OF MOTOR VEHICLE}

For the purpose of finding vibration of motor vehicles and drivers reaction during the N-Earthquake and the $\mathrm{C}$-Earthquake, questionnaire survey was made in Akita-ken (N-Earthquake) and Chiba-ken (C-Earthquake). For the N-Earthquake, ten firms consisting of 6 taxi companies, 3 trucking companies and 1 sightseeing bus company in Akita City and Noshiro City were selected, and questionnaires were sent to ten vehicle drivers in each firm (100 drivers in total $)^{2)}$. Unidentified replies to the questionnaire were

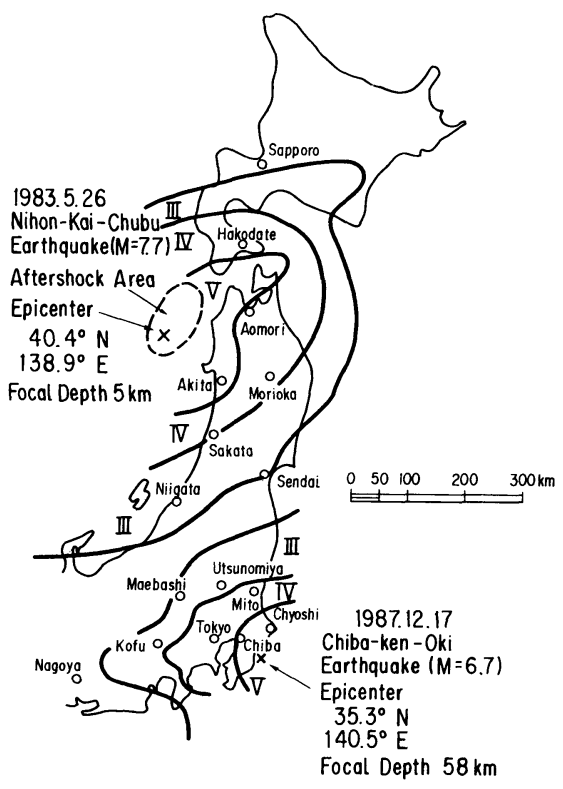

Fig. 1 Distribution of Seismic Intensity.

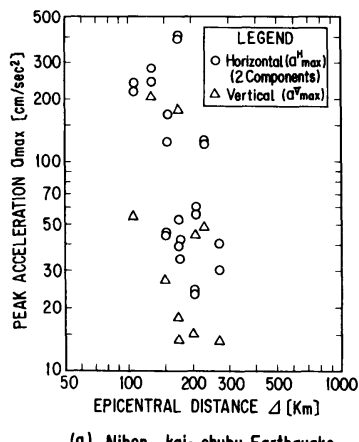

(a) Nihon-kai-chubu Earthquake

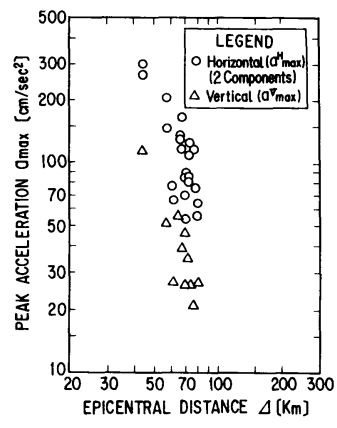

(b) Chibo-ken-oki Earthquake

Fig. 2 Attenuation of Peak Ground Accelerations. 
asked. This survey was conducted from June 21 to July 2, 1983, approximately one month after the occurrence of the $\mathrm{N}$-Earthquake. Ninety six replies were returned with the recovery rate of $96 \%$. Because the reply to the questionnaire was asked through companies, the recovery rate was extraordinarily high. Among 96 replies recovered in total, ten vehicles were being driving far from the regions without sensing significant vibration. Therefore, the ten vehicles were excluded, and only 86 replies were reviewed.

For the C-Earthquake, 27 companies consisting of 21 taxi companies and 6 tracking companies were selected in Chiba-ken, and the same questionnaires were sent to 405 drivers. The survey was made from December 21 to December 25, 1987, approximately one week after the occurrence of the C-Earthquake. Replies were obtained from 261 drivers with the recovery rate of $64.4 \%$.

Questions asked in the questionnaire comprises 13 items in total. Main items are as indicated below.

1) Location and traveling situation of motor vehicle at the time of outbreak of the earthquake, and sex, age and driving career of driver

2) Did the driver immediately notice the occurrence of earthquake? How did he recognize it ?

3) Driving safety during earthquake

4) Direction of prevailing vibration of motor vehicle

\section{ANALYSIS OF RESULT OF QUESTIONNAIRE}

\section{(1) Location and driving situation}

Effective replies were classified in terms of the location and driving situation of motor vehicles at the outbreak of the earthquakes. Fig. 3 shows the vehicle location in municipal unit. During the $\mathrm{N}$-Earthquake, the motor vehicles analyzed were distributed in the range of about $80 \mathrm{~km}$ from Minehama Village in Yamamoto County in the north to Akita City in the south. However, the number of motor vehicles in three cities of Akita, Noshiro and Oga was large, and $86 \%$ of motor vehicles analyzed were located in these cities. Among 86 vehicles 22 were in stop state at the time of outbreak of the earthquake. During the C-Earthquake, the motor vehicles analyzed were distributed in the range of $80 \mathrm{~km}$ and $90 \mathrm{~km}$ in NS and EW, respectively. The number of vehicles was large in Chiba City, Mobara City, Choushi City, Ichihara City, Tougane City and Kashiwa City, and $75 \%$ of the total were located in these cities. Among 261 vehicles, 116 were in stop at the time of the earthquake.

Drivers were all male in both earthquakes, and 3 teen-agers, 11 in twenties, 28 in thirties, 38 in fourties, 4 in fifties or older, and 2 unidentified in the $\mathrm{N}$-Earthquake, and 3 teen-agers, 21 in twenties, 69

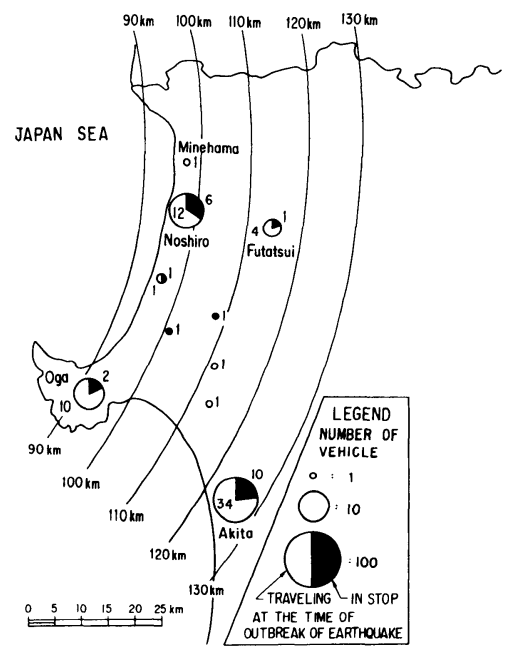

(a) Nihon-kai-chubu Earthquake

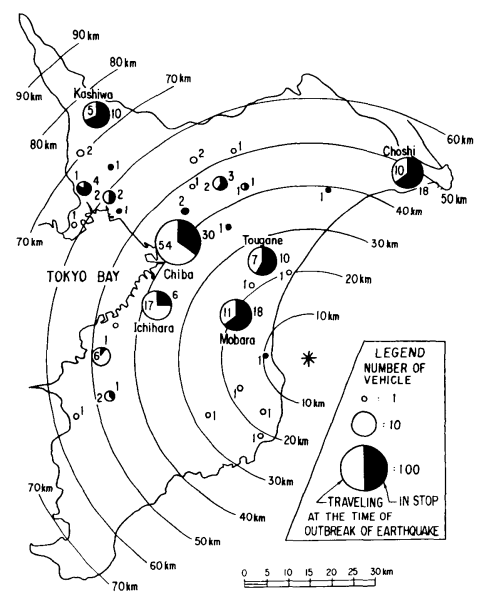

(b) Chiba-ken-oki Earthquake

Fig. 3 Vehicle Location in Municipal Unit. 
in thirties, 100 in fourties, 63 in fifties or older and 5 unidentified in the C-Earthquake. Averaged age of drivers was 39.8 (N-Earthquake) and 43.4 (C-Earthquake), and averaged driving history was 16.6 years (N-Earthquake) and 20.9 years (C-Earthquake).

With respect to the kind of motor vehicles, there were 42 ordinary passenger cars $(67 \%), 20$ large-sized motor vehicles $(31 \%)$ and two other motor vehicles (3\%) in the N-Earthquake, and 209 ordinary passenger cars (80\%), 36 large-sized motor vehicles (14\%) and other motor vehicles $(6 \%)$ in the C-Earthquake.

Traveling speed at the time of earthquake was as shown in Fig. 4 and was mostly between 31 and $40 \mathrm{~km} / \mathrm{h}$ in both earthquakes.

\section{( 2 ) Driver's degree of recognition of earthquake}

During the N-Earthquake, 36 drivers (56.3\% of the total number of 64 ) immediately recognized the occurrence of the earthquake during traveling and 26 drivers (40.6\%) recognized it later, so that $96.9 \%$ of all the drivers were aware of the earthquake as shown in Fig. 5. However, two drivers (3.1\%) were completely unaware of the outbreak of earthquake. One of them was driving ordinary an passenger car through Akita City while the other was driving a large-sized vehicle through Futatsui Town. It is very interesting that there was a few drivers who were completely unaware of the outbreak of the earthquake when traveling in the region with the seismic intensity $\mathrm{V}$.

During the C-Earthquake, 76 drivers (52.4\% of the total number of 145) immediately recognized the occurrence of the earthquake during traveling and 63 drivers (43.5\%) recognized it later. Thus, proportion of the drivers who were aware of the earthquake is $95.9 \%$. However, 6 drivers $(4.1 \%)$ were completely unaware of the earthquake. The proportion of the drivers who immediately recognized, recognized later and were completely unaware of the outbreak of the earthquake are very similar between the two earthquakes.

Only for C-Earthquake, the driver's recognition of earthquake was also studied for the drivers in stop at the time of outbreak of earthquake (refer to Fig. 5). The proportion of drivers who immediately recognized the C-Earthquakes was $83.6 \%$ for the drivers who were in stop. This is significantly higher than the same proportion of the drivers who were traveling at the time of C-Earthquake (52.4\%). It is important to note

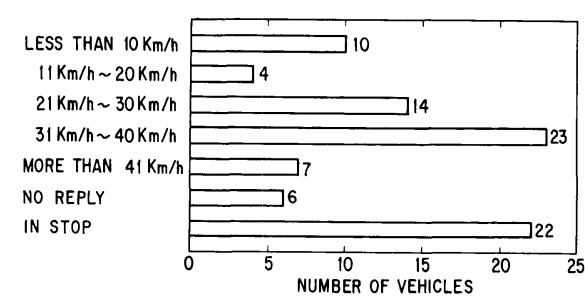

(a) Nihon-kai-chubu Earthquake

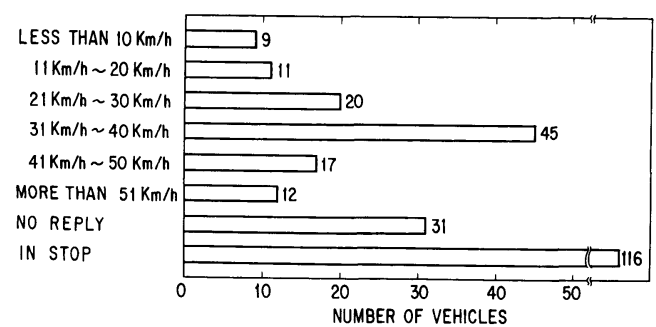

(b) Chiba-ken-oki Earthquake

Fig. 4 Traveling Speed at the Time of Earthquake.

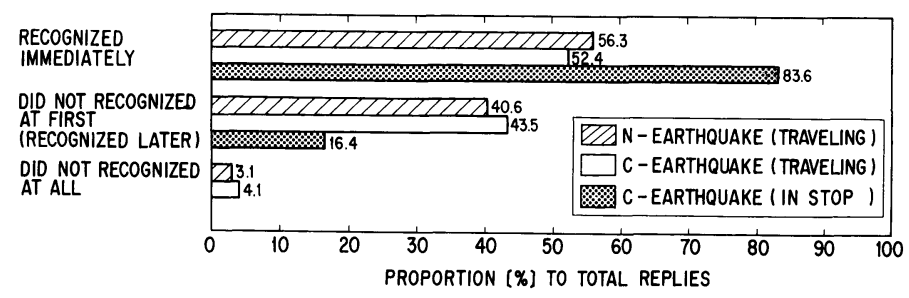

Fig. 5 Driver's Degree of Recognition of Earthquake. 
that the proportion of drivers who immediately recognized the earthquake strongly depend on whether drivers are traveling or in stop.

\section{(3) How drivers immediately recognized earthquake}

How the drivers immediately recognized the earthquake (there are plural replies) are examined and classified as shown in Fig. 6. Examined are 36 and 76 drivers who were traveling during N- and C-Earthquake, respectively, as well as 97 drivers who were in stop at the time of outbreak of C-Earthquake. According to Fig. 6, approximately $50 \%$ of total replies indicates the abnormal vibration of vehicles, followed by swinging of electric poles and street signs (23-29\% of total replies) and vibration of houses (11-18\%). No significant difference can be seen in the replies between the two earthquakes, and between the drivers who were traveling and those who were in stop at the time of C-Earthquake. Therefore it will be known that many drivers recognized the earthquake from the visual recognition of vibration of nearby road accessories and houses along the road in addition to the vibration of their own motor vehicles. Some drivers $(5-11 \%$ of the total) explained that they recognized the earthquake based on their experience in the past. Such drivers remembered the abnormal vibration of their vehicles and/or road accessories and houses along the road. This was possible probably because the residents in the Tohoku and Kanto Districts experienced several strong shaking in the past.

For those drivers who did not recognized the earthquake at first (26 and 63 drivers in $\mathrm{N}$ - and $\mathrm{C}$-Earthquake, respectively), their first incorrect impressions (plural replies) of the earthquake are classified and represented in Fig. 7. Many drivers (53\% in N-Earthquake and $64.6 \%$ in C-Earthquake) thought it as blowout of tire. A blowout of tire is mistakenly recognized probably because the driver can prevailingly recognized the vibration of vehicle due to earthquake in lateral direction (direction perpendicular to traveling direction of vehicle).

(4) Driving situation during earthquake

How the drivers felt when they experienced the earthquake during driving is shown in Fig. 8. Among 64 drivers who experienced $\mathrm{N}$-earthquake, $65.7 \%$ felt a danger and stopped their cars and $21.9 \%$ had some difficulty in handling steering wheel, so that $87.6 \%$ of the total drivers felt some obstacles to driving from

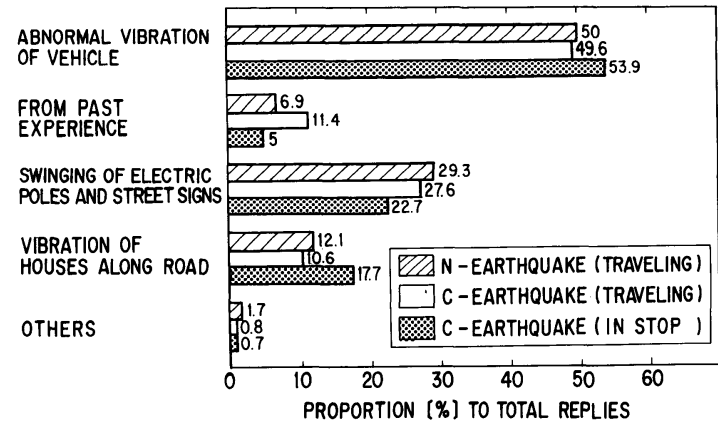

Fig. 6 Reason for Noticing the Outbreak of Earthquake.

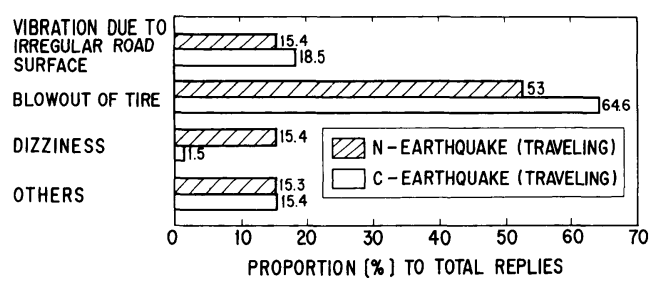

Fig. 7 First Incorrect Impression of Traveling Drivers Who did not Recognize Earthquake Immediately.

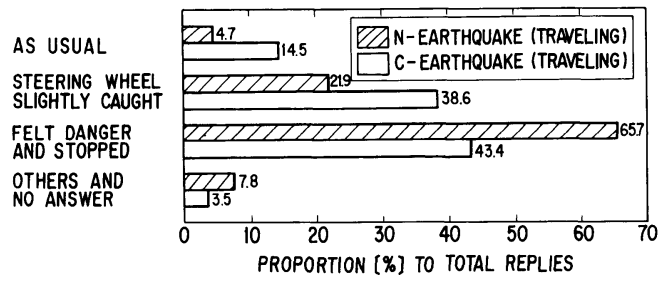

Fig. 8 Traveling Situation during Earthquake.

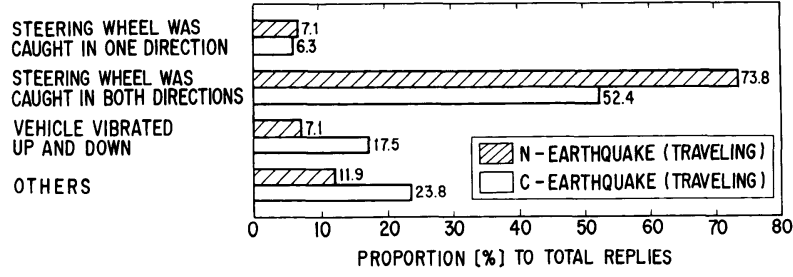

Fig. 9 Reason for Stopping after Feeling Danger. 
the earthquake. In the replies from drivers who experienced C-Earthquake, the proportion of drivers who felt a danger and stopped their cars is much less (43.4\%) than that in the N-Earthquake. This is presumably attributed to the fact that the intensity of ground acceleration was rather stronger in $\mathrm{N}$-Earthquake than in C-Earthquake (refer to Fig. 2). However including the drivers who had some difficulty in handling steering wheel $(38.6 \%)$, the proportion of the drivers who felt some obstacles to driving was $82 \%$ in C-Earthquake. This in nearly the same with the proportion developed during N-Earthquake.

Reasons why the drivers felt danger were asked to drivers who stopped their cars after feeling the danger. Fig. 9 shows that the majority of drivers felt a danger because they could not control the steering wheel at a time. This has some thing to do with the fact that the larger half of the drivers mistakenly felt a blowout of tire without immediately noticing the earthquake during driving and the fact that the prevailing vibrating direction of vehicle was lateral direction. When the steering wheel is caught and becomes uncontrollable, the vehicle will start a meandering motion, but this is the motion relative to the road surface, i. e., the road surface vibrate during an earthquake but the vehicle continues to travel straight in the original direction because of vehicle's inertial force. Therefore, if an earthquake occurs during traveling, the vehicle itself travels straight since the steering wheel is caught. In the case, if the driver tried to forcibly fix the steering wheel, the vehicle will begin to vibrate in the direction perpendicular to its traveling direction as the road surface vibrates. This is obviously more dangerous situation, because of possible overturning of the vehicle. This is greatly different from the traveling of trains on railway track.

(5) Vibration direction of vehicles

Prevailing direction of vibration of vehicles was surveyed as shown in Fig. 10. The majority of drivers (68. $8 \%$ and $48.3 \%$ of the total during $\mathrm{N}$ - and C-Earthquake, respectively) who were traveling at the time of outbreak of earthquake indicated vibration in lateral direction. This occurs probably because the intensity of the vertical earthquake ground motion is almost one-third smaller than the horizontal component ${ }^{3)}$, and also this seems to be related with the vibration of vehicle itself during traveling, i. e., the motor vehicle traveling straight is normally vibrating in up-and-down direction because of unevenness on road surface. Furthermore, vehicles are likely to be shaken in the traveling direction during accelerating and/or breaking the speed. This seems the reason why the majority had noticed the vibration mainly in lateral direction.

However it is interesting to note here that proportion of the drivers who felt lateral vibration during their driving was much larger during $\mathrm{N}$-Earthquake than during $\mathrm{C}$-Earthquake. This seems to be caused by ground motion characteristics because other conditions such as kind of vehicle and averaged speed were almost the same between the two earthquakes. Fig. 11 shows a ratio of peak ground acceleration between

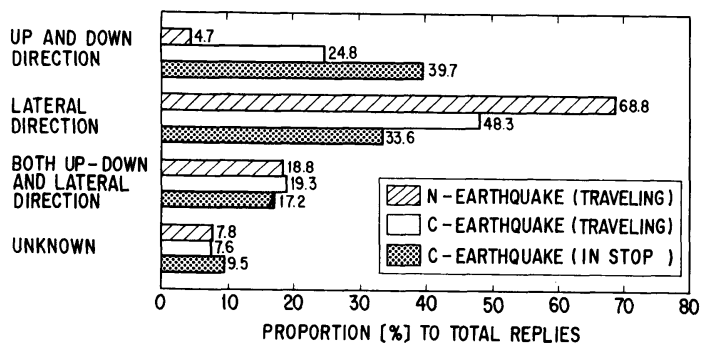

Fig. 10 Prevailing Direction of Vibration of Vehicle.

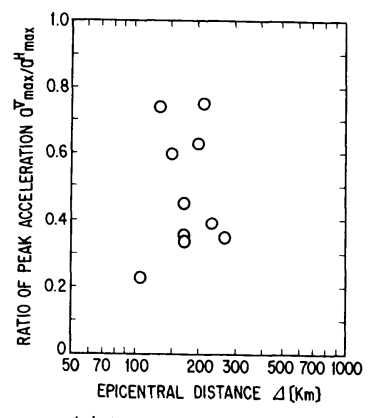

(a) Nihon-kai-chubu Earthquake

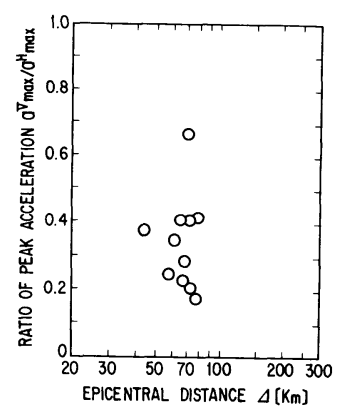

(b) Chibo-ken-oki Earthquake

Fig. 11 Ratio of Peak Ground Acceleration between Vertical and A Larger Component among the Two Horizontal Components. 
vertical and one of the larger components of the two horizontal components. Because scatter of the ratio depending on site is considerable, it is difficult to correlate directly Fig. 11 with driver's replies. However it seems difficult to explain that the ratio was appreciably smaller in N-Earthquake than in C-Earthquake. Further study is required to correlate the prevailing direction of vehicle vibration with characteristics of ground motion.

It is also interesting in Fig. 10 to note a significant difference in prevailing direction noticed by drivers who were traveling and in stop at the time of outbreak of $\mathrm{C}$-Earthquake. As described above, the majority of drivers (48.3\% of the total) who were driving at the time of outbreak of earthquake indicated lateral vibration as the most prevailing vibration. However, the most prevailing vibration direction of vehicle noticed by the drivers who were in stop during the earthquake was vertical vibration (39.7\% of the total) followed by lateral vibration (33.6\%). It is again interesting to note that the number of drivers who felt the vertical vibration was larger than those who felt the lateral vibration in spite of the fact that ground acceleration was obviously smaller in vertical direction than in horizontal direction. Vehicles are elastically supported by tires and springs. However, because contribution of the springs is limited in axial and lateral vibration, the body of vehicle would be considered to be supported by only tires in axial and lateral directions. Therefore, the fundamental natural frequency of the body is very high in these directions. On the other hand, in vertical vibration of the body supported by springs and tires, the fundamental natural frequency is generally $2-3 \mathrm{~Hz}$, which is close with the predominant frequency of ground shaking during an earthquake. Therefore, amplification due to resonance seems to be the reason to cause the noticeable vibration of vehicle in vertical direction.

\section{CONCLUSION}

For aiming to study vibration characteristics of motor vehicles and driver's reaction during an earthquake, questionnaire survey was made for drivers who were in driving through a region with the JMA seismic intensity of V during the Nihon-kai-chubu Earthquake of 1983 and the Chiba-ken-oki Earthquake of 1987. From the results presented herein, the following conclusions may be deduced ;

(1) Degree of driver's recognition of an earthquake highly depends on driving situation. During the Chiba-ken-oki Earthquake, proportion of the drivers who immediately recognized the occurrence of the earthquake is $84 \%$ for the drivers who were in stop at the time of outbreak of earthquake, while it is only $52 \%$ for the drivers who were traveling.

(2) Proportion of the traveling drivers who immediately recognized, recognized later and were completely unaware of the outbreak of the earthquake was very similar between the two earthquakes, and it is about $54 \%, 42 \%$ and $4 \%$, respectively.

(3) Approximately $50 \%$ of the total drivers immediately recognized the outbreak of the earthquake from the abnormal vibration of vehicles, followed by swinging of electric poles and street signs (about $26 \%$ ) and vibration of houses (about 15\%). No significant difference can be seen in this reply between the two earthquakes, and between the drivers who were traveling and those who were in stop at the time of the earthquake.

(4) First incorrect impressions of the drivers who did not recognized the earthquake immediately during traveling is blowout of tire (about $60 \%$ ) and vibration due to irregular road surface $(16 \%)$. This is very similar between the two earthquakes.

(5) Proportion of the traveling drivers who felt a danger and stopped their cars is $66 \%$ during the Nihon-kai-chubu Earthquake, which is much larger than that during the Chiba-ken-oki Earthquake (43\%), probably reflecting the fact that the intensity of ground shaking was rather stronger in the Nihon-kai-chubu Earthquake than in the Chiba-ken-oki earthquake.

(6) Prevailing direction of vehicle noticed by the drivers is significantly different between drivers who were traveling and those who were in stop at the time of outbreak of the earthquake. It is lateral 
vibration for the drivers who were traveling and vertical vibration for the drivers who were in stop.

\section{ACKNOWLEDGMENT}

The authors express their sincere appreciation to the taxi and trucking companies for their efforts to reply to the questionnaire, and personnels of the Tohoku and the Kantoh Regional Construction Bureaus of the Ministry of Construction for their supports for conducting the survey. Special thanks are also extended to Mr. Keiichi Tamura, a research engineer of the Ground Vibration Division of the Public Works Research Institute, for his help for surveying the ground motion characteristics.

\section{REFERENCES}

1) Tamura, K. : Earthquake and Earthquake Ground Motion, Prompt Report on Damage Caused by the Nihon-kai-chubu Earthquake of 1983, Report of Public Works Research Institute, Vol. 165, 1985.3.

2) Kawashima, K. and Kanoh, T. : Effects of Earthquake on Driving of Vehicles-A Case Study for the Nihon-kai-chubu Earthquake of 1983--, Civil Engineering Journal, Vol.30, No. 1, 1988.1.

3) Kawashima, K., Aizawa, K. and Takahashi, K. : Attenuation of Peak Ground Motions and Absolute Acceleration Response Spectra of Vertical Earthquake Ground Motion, Proc. of JSCE, Structural Eng./Earthquake Eng., Vol. 2, No.2, 1985.

(Received February 3 1989) 